\title{
Low weight at birth can be an indicative in childhood as a marker of metabolic syndrome and hypertension
}

\begin{abstract}
As low weight at birth can be a marker for future risk factors for cardiovascular diseases, public school children who had this positive history were studied $\mathrm{S}$ to nutritional status, lipids, glucose, uric acid, blood pressure and socioeconomic conditions. The main interest of the investigation is to find statistically significant correlations among data collected from young public school children from a city outside of the capital of Sao Paulo in Brazil. Results: risk factors for metabolic syndrome presented higher impact considering blood pressure and socioeconomic conditions, calling for better prenatal care and surveillance plus intervention in the low weight at birth children.
\end{abstract}

Keywords: low weight at birth, cardiovascular, risk factors, blood pressure, socioeconomic status, cholesterol, glucose and lifestyle
Volume 5 Issue 6 - 202I

\author{
Abel Pereira,' Anita LR Saldanha,' Ana \\ Paula Pantoja Margeotto,' Tereza Luiza \\ Bellincanta, ${ }^{1}$ André LV Gasparoto, ${ }^{2}$ Tatiana \\ Abrão,' Fernando H Guarnieri, ${ }^{3}$ Tania LR \\ Martinez' \\ 'Nephrology Department, BP - A Beneficência Portuguesa de \\ São Paulo, São Paulo, Brazil \\ ${ }^{2}$ Intensive Care Unit, BP - A Beneficência Portuguesa de São \\ Paulo, São Paulo, Brazil \\ ${ }^{3}$ IESP-UERJ - Universidade do Estado do Rio de Janeiro - Rio de \\ Janeiro, Brazil
}

Correspondence: Tania Leme da Rocha Martinez, BP - A Beneficência Portuguesa de São Paulo Rua Comandante Ismael Guilherme, 358 - Jardim Lusitânia, CEP 0403।-120 - São Paulo SP, Brazil, Tel 55 | | 98323-9863, Fax 55 || 3842-3789,

Email tamar@uol.com.br
Received: November 16, 2021 | Published: December 24, 2021

\section{Background and aims}

Low weight at birth has been described as a marker for various future health effects complications, such as risk factors for cardiovascular disease. ${ }^{1-4}$

Evaluation of risk factors for metabolic syndrome in public schools children that were low weight at birth and plan to promote its prevention in childhood and adolescence.

\section{Methods}

A total of 450 public schools students who had presented a low weight at birth, under $2.5 \mathrm{Kg}$, ages 02 to 19 years were studied: nutritional status (Waterloo till 6 years and by Body Mass Index for the older group), Total Cholesterol, HDL Cholesterol, LDL Cholesterol and Triglycerides, glucose, uric acid, blood pressure and socioeconomic conditions. Statistics: Chi-squared and Fisher test.

\section{Results}

Nutritional status correlated with a 2.75 probability of overweight in the group that was not low weight at birth. Total cholesterol divided in tertiles did not show differences, neither did LDL or HDL fractions or triglycerides. Blood pressure presented association by itself with the number of risk factors as diastolic $(p<0.039)$ in Figure 1 , and as systolic there was a trend with the same association $(\mathrm{p}<0.067)$. These results point to susceptibility in the low weight at the birth group for peripheral vascular resistance to environmental changes. The socioeconomic status difference was significant, higher prevalence in the less than threefold minimum wage classification $(\mathrm{p}<0.0030)$.

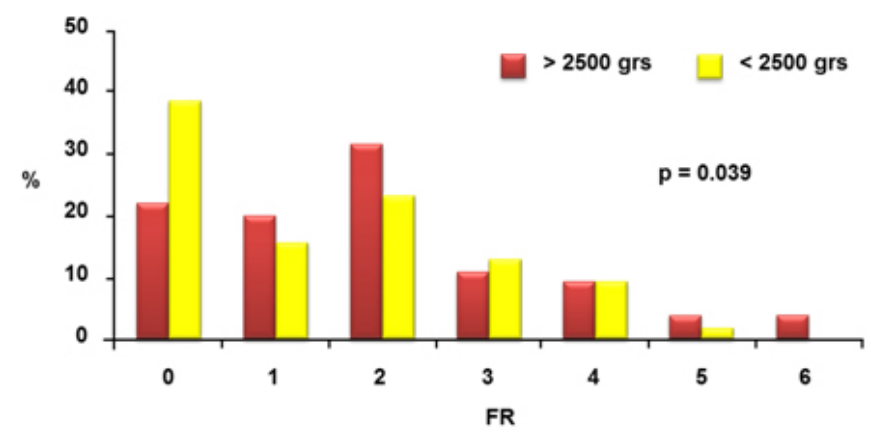

Figure I Diastolic blood pressure and number of risk factors.

\section{Conclusion}

As already better documented with adults, risk factors for metabolic syndrome presented higher impact considering blood pressure and socioeconomic conditions. The established association of this syndrome with insulin resistance and even with future diabetes is a signalization for precaution of cardiovascular disease.

These data lead to the conclusion that prematernal care must be improved and blood pressure plus all risk factors be taken care of periodically and orientation for intervention applied whenever necessary in low weight at birth children and adolescents.

\section{Acknowledgments}

None. 


\section{Conflicts of interest}

No conflict of interest.

\section{References}

1. Du Preez A, Leveson J, Zunszain PA, et al. Inflammatory insults and mental health consequences: does timing matter when it comes to depression? Psychol Med. 2016;46(10):2041-2057.

2. Raiten DJ, Sakr Ashour FA, Ross AC, et al. Inflammation and Nutritional Science for Programs/Policies and Interpretation of Research Evidence (INSPIRE). J Nutr. 2015;145(5):1039S-1108S.
3. Lacey RE, Bartley M, Kelly-Irving M, et al. Adverse childhood experiences and early life inflammation in the Avon longitudinal study of parents and children. Psychoneuroendocrinology. 2020;122:104914.

4. Slopen N, Loucks EB, Appleton AA, et al. Early origins of inflammation: An examination of prenatal and childhood social adversity in a prospective cohort study. Psychoneuroendocrinology. 2015;51:403-413. 